\title{
EL MIEDO COMO ARMA DE DOMINACIÓN: ADMIRACIÓN, PAVOR Y VICTORIA EN LA IMAGEN DEL REY GUERRERO EN EL HELENISMO INICIAL
}

\author{
FEAR AS WEAPON OF DOMINATION: ADMIRATION, \\ DREAD AND VICTORY IN THE WARRIOR KING'S IMAGE \\ IN THE EARLY HELLENISTIC WORLD
}

POR

\author{
Antonio Ignacio Molina Marín*
}

\section{RESUMEN - ABSTRACT}

El rey fue la figura más importante de todo el período helenístico. Fue un guerrero invencible, un gobernante sabio, dios, general y curador. Todos estos aspectos sobre la monarquía helenística son bien conocidos, sin embargo hay una cuestión que no ha sido estudiada por los investigadores, es decir, la capacidad de los reyes helenísticos para hacer huir a sus enemigos conmoviéndolos por el miedo con su mera presencia. En este artículo analizamos historias relacionadas con Pérdicas, Olimpíade, Pirro y Alejandro Magno. Nuestra opinión es que todas estas historias están basadas en el mismo modelo, la lucha entre Aquiles y los troyanos en la Ilíada (XVIII 203-23). La égida es estudiada como la justificación mítica de la invencibilidad y terribilidad de los reyes. Además, contemplamos la posibilidad de que este fenómeno estuviese asociado con los reyes de Macedonia antes de Alejandro.

The King was the most important figure of all the Hellenistic period. He was an invincible warrior, wise ruler, god, general and medicine man. All these aspects of Hellenistic kingship are well known, however there is one subject that has not been studied by scholars, namely the capacity of Hellenistic kings to scare their enemies with their mere presence. In this paper we analyze stories attaching to Perdiccas, Olympias, Pyrrhus and Alexander the Great. Our opinion is that all these stories are based on the same model, the fight between Achilles and Trojans in the Iliad (XVIII 203-23). The aegis is studied as the mythical justification of the invincibility and terribleness of the kings. Furthermore, we consider the possibility that this phenomenon was associated with the Macedonian kings prior to Alexander.

\section{Palabras Clave - Keywords}

Reyes helenísticos; Alejandro Magno; Macedonia; Guerrero invencible; Medusa; Phobos; Pan; Égida.

Hellenistic kings; Alexander the Great; Macedonia; Invincible warrior; Medusa; Phobos; Pan; Aegis.

El presente artículo analiza la monarquía macedonia y helenística en lo referente a temas como su relación con el mundo homérico, su carisma y el papel de la victoria como legitima-

\footnotetext{
* Doctor en historia antigua por la Universidad de Murcia, miprofeignacio@hotmail.com.

** Queremos dar las gracias a Borja Antela-Bernárdez (Universitat Autònoma de Barcelona) y a Daniel Ogden (University of Exeter) por sus consejos y ayuda con este artículo.
} 
dora del poder del monarca, pero está especialmente centrado en la capacidad de los reyes y dirigentes macedonios para inspirar el pánico en sus enemigos.

\section{VICTORIA, CARISMA Y LEGITIMACIÓN ENTRE LOS REYES MACEDONIOS.}

Tras las conquistas de Alejandro Magno se extendió en toda la oikoumene una forma de gobierno que, si bien no era nueva, había sido abandonada en el mundo griego en virtud de otros sistemas como la democracia y la oligarquía: la monarquía.

Dicha institución macedonia ha sido objeto de un intenso estudio en los últimos años en lo concerniente a la naturaleza y autoridad de sus reyes ${ }^{1}$. También se han discutido las similitudes entre la monarquía macedonia y la homérica ${ }^{2}$, especialmente en la faceta del rey como conductor de hombres (cf. Suda s.v. "Basileia") que dirige a sus tropas en primera línea de batalla. No era infrecuente que los reyes al liderar la vanguardia de sus tropas encontrasen la muerte o una nueva cicatriz que añadir a las que ya poblaban su cuerpo (Arr. An. VII 10.1-2). En cualquier caso, no parece haber sido un hábito exclusivo del mundo helenístico, pues Demóstenes (Sobre la Corona, XVIII, 67) enumeró las muchas heridas que había recibido Filipo para encontrar la gloria. Una lista que recuerda a la dada por Plutarco (Moralia 327F-B) sobre las de Alejandro. Isócrates (Filipo II 3-4) rogaba a Filipo, en una de sus cartas, que se guardase de luchar de forma temeraria, pues si él moría el objetivo perseguido por ambos desaparecería, como en la inútil victoria de Ciro en la batalla de Cunaxa (401 a.C). Otros ilustres macedonios como Crátero (Plut. Éumenes 7.5-6) y Leónato (Diod. XVIII 15.3; Justin. XIII 5.14) murieron antes de alcanzar el poder con el que les tentaba el destino por arriesgar sus vidas en la batalla. Del líder macedonio y del gobernante helenístico se esperan muchas cosas, salvo que envejezcan en la retaguardia.

No obstante, durante y después de Alejandro encontramos cada vez más ejemplos de combates singulares o monomachiai. El general Erigio no duda en aceptar un duelo contra el jefe de sus enemigos y después mostrarle la cabeza cercenada del adversario a su rey (Curt. VII 4. 34-40). El propio monarca alentaba estos comportamientos audaces con su dadivosidad y su rol como distribuidor del honor en el espacio del banquete ${ }^{3}$. Ptolomeo I Soter no desaprovecha la oportunidad de presentarse ante sus lectores como un guerrero homérico cuando relata sus acciones militares en la India (Arr. An. IV 24.3-5). Tal vez el ejemplo más notorio de valor personal nos lo ofrezca Pirro del Épiro en su lucha contra el lugarteniente de Demetrio Poliorcetes, Pantauco ${ }^{4}$ (Plut. Demetrio 41. 3-4; Pirro 7.6-9).

También se ha destacado la intensa relación entre la legitimidad para gobernar y la victoria ${ }^{5}$. El rey-general helenístico es pieza clave del triunfo y la derrota. Hasta tal punto está identificado con el éxito que no puede ostentar el poder sin antes vencer ${ }^{6}$. La exigencia se vio reflejada en la titulación real: aniketos (invencible) o nikator (victorioso). La victoria, y no la

1 Existen dos corrientes historiográficas sobre la naturaleza de la monarquía macedonia, la primera defiende una autoridad limitada del rey por la asamblea: Granier, 1931; Hammond, 1989. La segunda interpretación sostiene que el rey tuvo un poder casi absoluto: Errington, 1974; Lock, 1977; Borza, 1990.

2 Cohen, 1995: 487-8; Carlier, 2000: 262-3; Gabriel, 2010: 6.

3 Plut. Alex. 39.2, recompensa a Aristón, el jefe de los peonios, con una copa de oro llena de vino al mostrarle la cabeza de un enemigo. Véase Roisman ( 2003: 306 y ss.) para el rol del rey como distribuidor de honores en su corte y Molina Marín (2009: 201-9) para la importancia del banquete macedonio como lugar en el que se reparten presentes.

4 Berve, 1926, II, nº 604: 298; Heckel, 2006: 189.

5 Antela-Bernárdez (2009: 164; 167-8) estudia este aspecto en las luchas por la sucesión en Macedonia y Bosworth (2003: 246-78) desde una perspectiva más centrada en los sucesores de Alejandro.

6 Romm, 2011: 238. 
herencia ${ }^{7}$, es la que legitima al monarca para poder gobernar, puesto que la derrota le priva del derecho a mandar o comandar tropas. Sólo así se entiende que los fundadores de los reinos helenísticos esperasen oficialmente al año 306 para ceñirse la corona (Plut. Demetrio 17-18). En efecto, tras la victoria en Salamina (Chipre) Antígono y Demetrio tomaron el título real ${ }^{8}$, siendo posteriormente imitados por el resto de los Diádocos (Ptolomeo, Seleuco, Casandro y Lisímaco). El interregnum de más de 3 años que se inició con la muerte de Alejandro IV no finalizó hasta que el prestigio de la victoria avaló a los sucesores de Alejandro Magno9.

El éxito no se comparte, pues el triunfo del oponente significa el deterioro del prestigio personal. El todopoderoso Antípatro sintió como su liderazgo decrecía entre sus tropas ante los éxitos de Éumenes ${ }^{10}$ (Arr. Succ, F 1.44-5). La competencia es absoluta y los reyes prefieren morir en combate antes que afrontar la derrota (Antígono; Lisímaco; Pirro), dado que ser vencido significa perder el trono ${ }^{11}$.

Por otro lado, el rey-general helenístico está dotado de un prestigio o charisma que puede lograr que los soldados de sus enemigos se pasen a su bando. Despertar la admiración entre sus hombres era algo que ya recomendaba Jenofonte (Ciropedia III 3.3.10; I 6.42) y cualquier monarca siguió esta máxima, pero en este período el prestigio del rey trasciende el espacio de su propio campamento. El jefe militar puede despojar a su adversario del apoyo de sus seguidores como si fuera una extensión más de su mutua rivalidad por hacerse con el triunfo. Son varios los motivos que podían empujar a los soldados a romper su juramento: la promesa de un mayor botín, un líder que compartía los pesares y peligros del combate con sus tropas o encontrar un señor más atractivo para quienes, como los mercenarios, buscaban garantías de futuras recompensas a la hora de vender su espada ${ }^{12}$.

A veces el carisma y la reputación de los líderes militares eran tan grandes que bastaba con saber que estaban en el ejército contrario para que los soldados se negasen a entrar en batalla. Eso fue lo que logró impedir el astuto Éumenes mediante una treta cuando los macedonios se enteraron de la presencia de Crátero (Plut. Éumenes 6-7). Demetrio decidió no llevar sus armas contra su compatriota Lisímaco y sí contra Pirro, por miedo a que sus hombres cambiaran de bando, pero, como descubrió el sitiador de ciudades, sus temores sobres sus soldados podían materializarse igualmente en un monarca extranjero como Pirro (Plut. Demetrio 44.6-7; Pirro 11.6).

Este hecho, la deserción de tropas macedonias en beneficio de un déspota extranjero, bien podría haberse debido a la proliferación de mercenarios en la guerra o bien a que el rey helenístico nunca tuvo una significación étnica, sino cualitativa. De hecho, la monarquía macedonia, modelo de la helenística, se jactaba de no ser autóctona y de proceder de Argos (Hdt. V 22; VIII 137; App. Siria 63).

Una circunstancia similar ocurre en el enfrentamiento entre Molón y Antíoco III, pero esta vez en plena batalla. Los soldados de Molón al ver al rey Antíoco desertan y se pasan al bando real. ¿El motivo?. Polibio (V 54) no lo especifica, pero deja claro que su decisión se tomó al percatarse de la presencia del rey, y que esta victoria de Antíoco aumentó el espíritu de lucha de sus soldados.

\footnotetext{
7 Waterfield, 2011: 144.

8 Grainger, 2007: 124.

9 Antela-Bernárdez, 2009: 171-2.

10 Berve, 1926, II, nº 317: 156-8; Heckel, 2006: 120-1.

11 La excepción fue Demetrio Poliorcetes que sobrevivió dos veces a la pérdida de la corona: Ipsos (301 a.C) y la invasión de Macedonia por Pirro (287 a.C). Véase Bosworth ( 2003: 278).

12 Austin (1986: 464-5) destaca la importancia del botín para mantener la lealtad de los soldados.
} 
Este don para conseguir que los enemigos deserten está vinculado a los rasgos anteriormente mencionados: exigencia de valor personal en la lucha y del triunfo. El monarca que poseyese las cualidades específicas que se esperaban de una persona regia podía acrecentar sus derechos al trono. Y una de esas cualidades es la de derrotar al adversario con el protagonismo de su persona. Hacer que los soldados de un enemigo se unan sin lucha es otra forma de victoria, y una especialmente importante, porque se obtiene por el carisma del rey a través de una monomachia simbólica contra el prestigio de su oponente (cf. Plut. Pirro 26). La victoria era doble, la legitimidad para ejercer el poder mayor.

\section{EL TERROR COMO CUALIDAD DEL REY MACEDONIO.}

Existe otro elemento estrechamente ligado al carisma de los reyes y a su búsqueda por obtener el triunfo que ha sido obviado por los investigadores. Nos referimos a la capacidad de aterrar de los señores del mundo helenístico. El primer indicio aparece en Arriano:

"Veían como cosa incierta el regreso a casa sanos y salvos, rodeados como se hallaban ahora por tantos pueblos belicosos que les cerraban el paso, de los cuales, unos aún no les estaban sometidos, es más parecían estar dispuestos a luchar bravamente por defender su libertad; y otros, a buen seguro, en seguida se sublevarían, al desaparecer con Alejandro el miedo

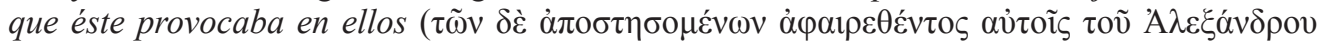
甲óßov). Aún más, creían que se hallaban ahora en medio de ríos infranqueables, y en suma, sin Alejandro todo se les hacía dificultades insolubles e irremediables"13 (Traducción de Guzmán Guerra, 1982).

El rey es capaz de infundir tanto miedo a sus enemigos que sus soldados no creen que puedan derrotar a los mismos pueblos que anteriormente habían sido vencidos por ellos, si su monarca no los acompañaba. Sin embargo, el pasaje podría ser una simple apreciación personal de Arriano o un medio para destacar la importancia de Alejandro en los acontecimientos ${ }^{14}$.

Mayor peso tiene el caso de Pérdicas ${ }^{15}$. Éste había sido designado quiliarca ${ }^{16}$ del Imperio por Alejandro y posiblemente lo nombró su sucesor cuando le entregó su anillo en su lecho de muerte (Curt. X 5.4, 6.4-5; Justin. XII 15.12; Diod. XVII 117.3; XVIII 2.4; Nep. Eum. 2.1). No fue un monarca, pero por el enorme poder que llegó a concentrar en sus manos pudo ser considerado como tal e incluso es posible que estuviese vinculado con la casa real macedonia ${ }^{17}$. Pese a la ausencia de un título real Pérdicas tenía más poder y autoridad que muchos reyes. Aunque ello no le libró de intentos de asesinato:

"Meleagro, tomando su silencio por una orden, envió una comisión en nombre del rey con el encargo de que hicieran venir a Pérdicas y con el mandato de darle muerte si ofrecía resis-

13 Arr. An. VI 12.2. Sobre la cualidad de los reyes macedonios, y de Alejandro en concreto, como conductores y guías de hombres véase el artículo de Jacob (1991: 5-40).

14 En una inscripción en la que se recogen los honores póstumos a Licurgo de Atenas, se habla de forma similar del

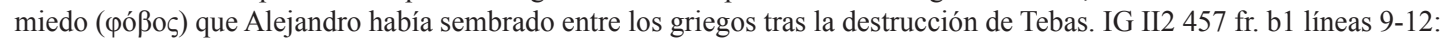

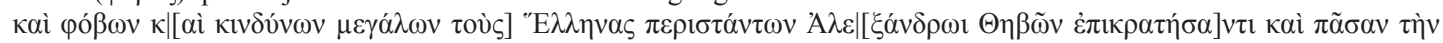

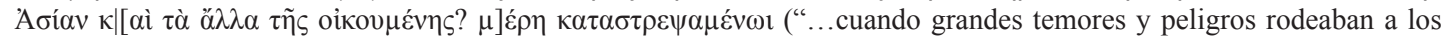
griegos, después de que Alejandro venciese a Tebas y sometiese toda Asia y otras partes de la oikoumene"). Texto griego procedente de Chaniotis (2012: 97; 119).

15 Berve, 1926, II, nº 627: 313-6; Heckel, 1992: 122-51; Heckel, 2006: 197-202.

16 Sobre este puesto ver Collins (2001: 259-83).

17 Cf. Curt. X 7.8: "Stirpe regia genitus", lo vincula a la familia de los Argéadas. 
tencia. Al serle anunciada a Pérdicas la llegada de los guardias, acompañado únicamente de 16 pajes de la cohorte real (pueris regiae cohortis) se plantó en el umbral de su casa y apostrofó a aquellos, llamándolos una y otra vez esclavos de Meleagro; los guardias asustados ante la firmeza de su ánimo y la expresión de su rostro, emprendieron la huida poco menos que fuera de sí (sic animi vultusque constantia terruit, ut vixmentis compotes fugerint)"18.

La expresión del rostro de Pérdicas es suficiente para asustar a veteranos curtidos en las guerras de Filipo y Alejandro. Sin embargo, pese a posibles manipulaciones, esta historia no ha sido puesta en duda por los investigadores ${ }^{19}$. Hay que destacar que, pese a no ser el rey, Pérdicas estaba acompañado por los Pajes Reales (Paides Basilikoi), que servían tradicionalmente al monarca macedonio ${ }^{20}$. Tras ser derrotado por Ptolomeo en Egipto el valor de Pérdicas le sirvió de poco, pues las simpatías de sus soldados se volvieron hacia el nuevo gobernador de Egipto, siendo finalmente asesinado por sus hombres de confianza (Diod. XVIII 36.4-5). Cualquiera que hubiese sido la razón por la cual Pérdicas pudo "espantar" a los hombres de Meleagro $^{21}$ desapareció con su derrota.

Olimpíade, al igual que en casos anteriores, fue capaz de conseguir que las tropas de AdeaEurídice abandonasen a la reina por el prestigio de su posición $(\alpha \hat{\xi} i \omega \mu \alpha)$ :

“Así, tan pronto como escuchó que Olimpíade estaba en Evia, en Macedonia, con su ejército, se apresuró a ir contra ella con la intención de resolver las cosas en una sola batalla. Cuando ambos ejércitos estuvieron frente a frente, los macedonios por respeto a la posición $(\alpha \dot{\alpha} \xi \hat{i} \omega \alpha)$ de Olimpíade y rememorando los beneficios que habían recibido de Alejandro, se cambiaron de bando. El rey Filipo y su corte fueron capturados inmediatamente, mientras Eurídice fue tomada cuando estaba de camino a Anfípolis con Policles, uno de sus consejeros. De este modo,

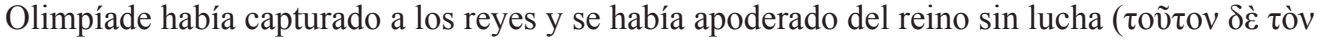

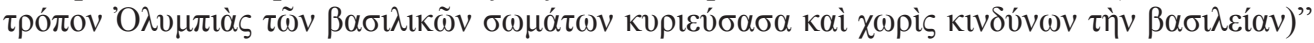
(Diod. XIX 11.2-4. Traducción propia).

La victoria de Olimpíade incrementó todavía más su carisma y ese hecho se reflejó en el cuarto y último cambio de nombre durante su vida: Estratónice ("la que vence al ejército"). Asentado su poder, gobernó en Macedonia desempeñando la epimeleia ${ }^{22}$ (regencia) de su nieto. La modificación de su onomástica estuvo íntimamente ligada con su triunfo, que fue uno de los hechos que la legitimaron para gobernar pese a su condición femenina. Lo sucedido concuerda más con los casos de deserción anteriormente vistos, pues a diferencia de Pérdicas no se dice de ella que su rostro fuese terrorífico o que inspirase temor entre los soldados. Sin embargo, Ateneo, citando a Duris de Samos (XIII 560F) dice que la madre de Alejandro vestía como una ménade cuando se enfrentó a Adea-Eurídice. Las ménades eran figuras dionisíacas que infundían temor en los hombres y Duris afirma que ambas marchaban al combate al ritmo de tambores, un instrumento asociado con las danzas guerreras (Cf. Str. X 3.7). ¿Lo que Diodoro consideró respeto pudo ser realmente miedo o una mezcla de ambas emociones?

Una mujer tan extraordinaria como Olimpíade nos vuelve a deleitar con otro de estos extraños casos en el que las similitudes con Pérdicas son mayores. Poco después de los acontecimientos relatados, Casandro terminó por ganar la guerra y se apoderó de Macedonia y de la familia de Alejandro. Entonces decidió llevar a juicio a Olimpíade, pero ante la preocupación

18 Curt. X 8.1-3. Traducción de Francisco Pejenaute Rubio, 1986.

19 Pese a que Ptolomeo intentó minimizar los logros de Pérdicas en hechos como los asedios de Tebas y Halicarnaso, no encontramos nada semejante en este pasaje. Véase: Errington, 1969; Yardley y Atkinson, 2009: 197-8.

20 Hammond, 1990: 261-90; Sawada, 2011: 403-6.

21 Berve, 1926, II, n494: 249-50; Heckel, 1992: 165-70; Heckel, 2006: 159-61.

22 Carney, 2006: 70 . 
que sentía por la posibilidad de que la asamblea de macedonios fuese convencida por la madre del difunto rey, el hijo de Antípatro mandó a sus secuaces para asesinarla:

"Casandro temiendo que la multitud podía cambiar de opinión si escuchaba a la reina defenderse y como eran recordados todos los beneficios que Alejandro y Filipo habían otorgado a toda la nación, envió a por ella 200 soldados bien equipados, ordenándoles asesinarla tan pronto fuese posible. En consecuencia, irrumpieron en la casa real, pero cuando vieron a Olimpíade, intimidados por su elevado rango, se retiraron con su misión inconclusa (ẃs

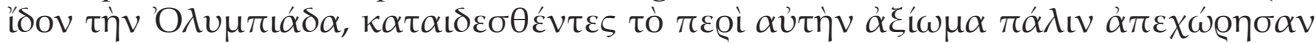

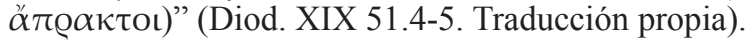

Diodoro atribuye de nuevo la retirada al elevado rango de Olimpíade, pero esta vez especifica que la decisión final se produjo cuando vieron a la reina. Lo cierto es que los macedonios no habían tenido anteriormente reparos en asesinar a gente de la edad o de la posición de Olimpíade. Su vinculación con Alejandro Magno no puede ser el único motivo. ¿Qué tenían tanto Olimpíade como Pérdicas en común como para poder hacer retroceder a sus enemigos?. Es difícil decirlo, pero su apogeo se inició por su vinculación con un miembro de la familia de los Argéadas, y su decadencia se manifestó con su participación en el asesinato de otro ${ }^{23}$.

Pirro es de sobra conocido por su valor y arrojo en la batalla. Su nombre y no su presencia provocaron como vimos la deserción de las tropas de Demetrio. No obstante, hay una ocasión en la que su mirada fue suficiente para detener, por momentos, la espada de su adversario:

"Al desenvainar Zópiro una espada ilírica para cortarle la cabeza, se volvió a mirar-

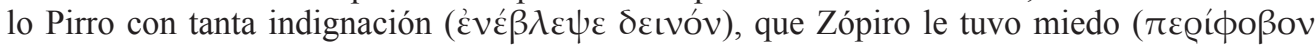
$\gamma \varepsilon v o ́ \mu \varepsilon v o v)$; y ya temblándole las manos, ya volviendo al intento, lleno de turbación y sobresalto, no al recto, sino por la boca y la barba, tarda y difícilmente se la cortó por último" (Plut. Pirro 34. Traducción de Antonio Ranz Romanillos, 1968).

En esta ocasión no hay duda alguna, la presencia del rey despierta miedo. Un miedo irracional que es capaz de hacer temblar a un soldado experimentado como Zópiro, pese a que Pirro está por completo indefenso. Una historia que debió ser transmitida por la propaganda del vencedor (Antígono Gónatas), como un gesto para dignificar la memoria de su oponente y el cargo que ocupó. Matar a un soberano nunca puede ser una tarea fácil para un simple hombre.

Existe un posible precedente para todos estos casos y es el enfrentamiento de Alejandro con los malios en la India. Como es de sobra conocido el macedonio se quedó aislado del grupo principal de sus hombres en medio del combate:

“...pero habiéndose roto la escala, colocados los bárbaros al pie del muro, le causaron desde abajo diferentes heridas; mas él, sin embargo de tener muy poca gente consigo, tuvo el arrojo de dejarse caer en medio de los enemigos, quedando, por fortuna, de pie; y habiendo recibido gran sacudimiento las armas, les pareció a los bárbaros que un resplandor y apariencia

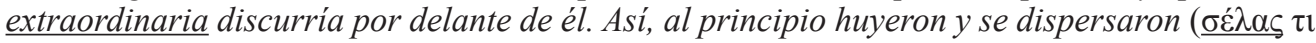

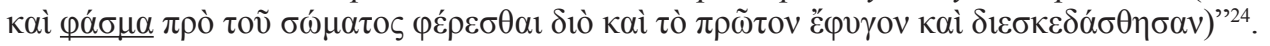

Como en los casos anteriores un único adversario conseguía hacer huir a numerosos enemigos al infundirles un miedo irracional. Sin embargo, aquí por primera vez se avanza en la

23 Alcestas el hermano de Pérdicas mató a Cinna (Arr. Succ. I 22-23; Polyaen. VIII 60); Olimpíade mandó ejecutar tanto a Adea-Eurídice como a Filipo III (Diod. XIX 11.2-7).

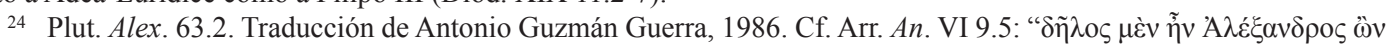

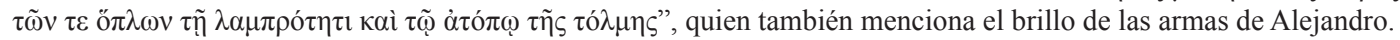


descripción del aspecto regio que resulta tan terrorífico para quienes huyen. Un resplandor $(\sigma \varepsilon ́ \lambda \alpha \varsigma)$ y una apariencia fantasmagórica $(\phi \alpha ́ \sigma \mu \alpha)$ envuelven a quién posee el don de ahuyentar a sus enemigos por su sola presencia.

\section{ORÍGENES MÍTICOS DEL TERROR}

Si entendemos que las historias anteriores de Pérdicas, Olimpíade y Pirro tuvieron un modelo o un paradigma que explicase su comportamiento y su cualidad, debe decirse, sin duda alguna, que debió ser Alejandro de Macedonia, no sólo por la cronología, sino por haber sido un referente para todos ellos. No obstante, el propio Alejandro también tenía sus propios modelos de imitación (Perseo, Heracles, Aquiles, Dioniso, etc.). Hace unos años Mossman ${ }^{25}$ demostró que el pasaje de Plutarco sobre el combate de Alejandro contra los malios se inspira en otro de la Ilíada (XIX 370ss), el momento en el que el Eácida Aquiles, antepasado por línea materna de Alejandro, se pone las armas que Hefesto ha hecho para él por encargo de su divina madre.

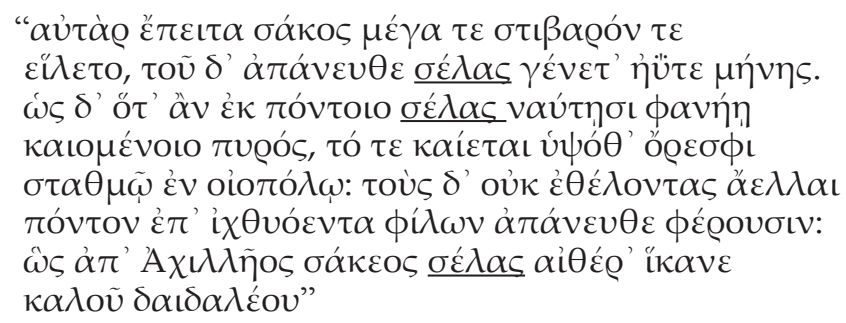

La coincidencia léxica hace que indudablemente exista una relación entre ambos pasajes y como señala Mossman: "Alexander is never more like Achilles than this, in his magnificent courage" (90). Ahora bien, desde el punto de vista de la temática hay otra escena de la Ilíada que tiene mayor similitud con la heroicidad de Alejandro ante los malios: el momento en el que Aquiles, revestido por la égida, ha puesto en fuga a cuántos enemigos se interponían entre el cuerpo del difunto Patroclo y su cólera:

"Atenea le echó sobre sus valientes hombros la floqueada égida ( $\alpha i \gamma \mid \hat{i} \delta \alpha \theta v \sigma \sigma \alpha v o ́ \varepsilon \sigma \sigma \alpha v)$, la diosa de la casta de Zeus coronó su cabeza de un nimbo áureo e hizo brotar de su cuerpo una inflamada llama ardiente... asi el fulgor de la cabeza de Aquiles llegaba hasta el cielo ( $\omega \varsigma \varsigma \alpha \pi^{\prime}$

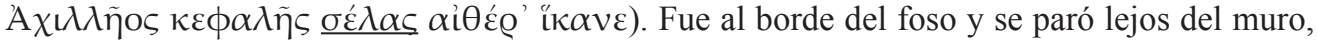
más a los aqueos no se unió por deferencia hacia el sagaz encargo de su madre. Allí se detuvo y dio un grito, que Palas Atenea a gran distancia llevó, y causó un indecible tumulto entre los troyanos... Nada más oír la broncínea voz del Eácida, se conmovió el ánimo de todos" (XVIII 203-206; 214-218; 222-223) (Traducción de Emilio Crespo, 1999).

La similitud es mayor, no sólo por la temática y el espacio (Aquiles espanta a sus adversarios cerca de un muro durante un combate), sino porque además vuelve a aparecer la palabra $\sigma \varepsilon ́ \lambda \alpha \varsigma$. Este pasaje de Aquiles sería el modelo mítico a través del cual se construyen las gestas de los otros. La "broncínea" voz de Aquiles que asusta a sus enemigos es otra cualidad que comparten, pues Plutarco (Pirro 8.1) dice que Alejandro y el epirota tenían poderosas voces. Una voz de tales características era la propia de un héroe. Cualquier lector de la Ilíada recor-

25 Mossman, 1988: 83-93. 
dara el epíteto que suele acompañar a Diomedes: "bueno en el grito de guerra" (Ilíada IX 30:

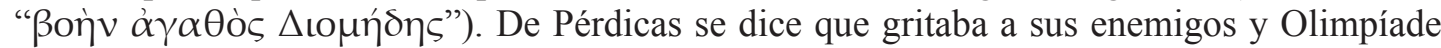
también debió hacerlo a los hombres de Adea Eurídice y Casandro.

Del texto de Plutarco se deduce que Alejandro también vistió la égida, pues de lo contrario no se habría producido el resplandor que ilumina su cuerpo. La égida dota a Aquiles y Alejandro de otra cualidad en común: Gorgo-Medusa. Vernant dice sobre Gorgo que es una potencia asociada al terror, pero a uno sobrenatural que paraliza al adversario: "Es el horror en estado puro, el Terror como dimensión de lo sobrenatural. En efecto, no es un miedo secundario ni motivado, no es consecuencia de la conciencia de peligro. Es previo a todo. Desde el principio y por sí misma Gorgo produce espanto porque aparece en el campo de batalla como un prodigio (téras), un monstruo (pelor), en forma de cabeza (kephalé), terrible y aterradora (de ver y oír) (deiné te smerdne te), con una cara de ojos terribles (blosuropis) que lanza una mirada de espanto (deinòn derkoméne)... el brillo de la mirada de Gorgo se une al resplandor del bronce deslumbrante; el rayo parte de la armadura y el casco para sembrar el pánico hasta el cielo. La grotesca boca del monstruo, abierta de par en par, evoca el grito de guerra de Aquiles, resplandeciente bajo la llama que Atenea hace brotar de su cabeza, profiere tres veces antes de lanzarse a la batalla" ${ }^{26}$. El grito, la mirada terrible y el resplandor son otras características que hemos visto en los casos anteriormente citados.

El poder de ahuyentar a sus enemigos sin sus armas no es una habilidad específica ni de Aquiles, ni del escudo que Alejandro tomó en Troya ${ }^{27}$. El Pelida tiene éxito porque Atenea pone la égida sobre sus hombros. Es la Gorgona, Medusa, aquella que tiene la muerte en sus ojos, la que posee esa capacidad, sin ella el guerrero por excelencia no se atreve a volver a la lucha desarmado. De Héctor también se dice en la Ilíada (VIII 347) que "sus ojos tienen la mirada de la Gorgona". Luego no es una cualidad asociada a una familia o a un pueblo en concreto. El portador de la égida se asemeja a aquel que ha recibido la areté (excelencia), puesto que no son posesiones ni exclusivas ni eternas. La comunidad y Atenea pueden quitárselas o dárselas según su capricho, aunque tanto en Aquiles como en Alejandro hay algo que los hace especialmente receptivos a dicha posibilidad: su carisma regio.

\section{LOS REYES MACEDONIOS Y LA ÉGIDA}

Dando por supuesto que Gorgo/Medusa es el origen mítico que da vida a estos hechos, debemos analizar la relación de los personajes estudiados con ella. Pérdicas aparentemente no tiene ninguna. En cambio, Olimpíade y Pirro eran molosos y, por lo tanto, descendientes directos de Aquiles que, como hemos visto, había portado la égida. Los Eácidas presumían de ser descendientes tanto de la dinastía troyana como de la familia de Aquiles, puesto que su fundador, Moloso, fue hijo de Andrómaca y Pirro (Plut. Pirro 1.2). Tampoco era infrecuente que los miembros de la dinastía molosa llevasen nombres troyanos ${ }^{28}$. Al igual que en Macedonia los valores homéricos parecen haber estado vigentes en el Épiro.

¿Qué decir de Alejandro?. Mitad macedonio y mitad epirota, descendiente de Perseo, Heracles y Aquiles. Imitador destacado entre cuántos emularon al hijo de Peleo ${ }^{29}$. Calístenes

Vernant, 1996: 55-6.

27 Arr. An. VI 9.3; Diod. XVII 21.2.

28 Carney, 2006: 16.

29 Sobre la imitación de Aquiles: Ameling, 1988; Cohen, 1995; Antela-Bernárdez, 2007: 90-94; Molina Marín, 2012 : $60-78$. 
describió a Alejandro llevando la égida ${ }^{30}$. Gorgo también se puede encontrar en la iconografía de Alejandro. En el famoso y mal llamado Mosaico de Issos aparece llevando la cabeza de Medusa sobre su coraza ${ }^{31}$. El Alejandro Aegiochus (portador de la égida) es representado con un gorgoneion a modo de insignia en la solapa ${ }^{32}$. El cabello leonado y desordenado de las imágenes del macedonio recuerda a la serpentea melena de las gorgonas. Incluso se ha conservado una escultura de Alejandro con los atributos de Medusa. Se trata de un bloque de piedra caliza encontrado en la antigua Etruria que fue utilizado para adornar un trono del siglo III a. C., y que representa a Alejandro con las serpientes y alas de Medusa ${ }^{33}$. Por último, como ya ha señalado Stewart, la relación entre Alejandro y la égida podría estar implícita en su propio nombre, puesto que Alex + andros significa: "ahuyentador de hombres" 34 .

Era una práctica muy común entre los combatientes griegos invocar al miedo con elementos como Gorgo, pero el caso de Olimpíade no puede ser circunscrito al ritual del guerrero, sino a su posición $(\dot{\alpha} \xi \hat{i} \omega \mu \alpha)$ y a su relación con la monarquía. De hecho, todos los ejemplos mencionados proceden de personajes que estaban ligados a la realeza o que ostentaban el más alto liderazgo. Estos individuos siempre consiguen hacer huir a sus enemigos por su apariencia terrible o por sus gritos. Y la mirada es el instrumento más frecuente para despertar ese miedo irracional y primitivo en el otro ${ }^{35}$. Es necesario recordar que en griego el miedo es una emoción externa que alguien introduce en quien lo experimenta (cf. Hdt. IV 203.3; VII 10; VIII 38), y los ojos son el receptor y emisor de este intercambio.

Ahora bien, esto no quiere decir que el poder de infundir miedo en sus adversarios fuese una virtud exclusiva entre los reyes del Épiro. Es posible que la fuerza que la égida daba a los guerreros fuese, al igual que la areté, propensa a perdurar en determinadas líneas de sangre, como ocurría con su fama, si tenían algún antepasado mítico relacionado con Medusa o la mencionada égida. Desde esta perspectiva, hay indicios que permiten sugerir que Gorgo también tenía una especial importancia en Macedonia. De ser correcta esta suposición todos los casos estudiados tendrían una misma conexión, pues Pirro gobernó este reino en dos ocasiones, aunque por un breve período de tiempo (287-84; 273-2 a.C).

En primer lugar, el nombre Pérdicas recuerda en su primera sílaba (Per-) al de Perseo, el héroe que mató a Medusa ${ }^{36}$. Los Argéadas eran descendientes de Heracles, bisnieto de Perseo, el gorgonicida. A través de ambos, los reyes de Macedonia estaban vinculados a Zeus, portador de la égida ${ }^{37}$ (Aigiochos). El grito de guerra macedonio ("alalai") estaba consagrado a Enialio (Plut. Moralia 349c), una personificación de Ares, pero tenía la misma función y efecto que el chillido de $\mathrm{Gorgo}^{38}$. Se han encontrado monedas con la cabeza de la gorgona en Macedonia ${ }^{39}$. Tampoco debemos olvidar que la égida ( $\alpha \dot{i} \gamma$ ís) estaba hecha con la piel de la cabra Amaltea. Y la primera capital de Macedonia, Aigai (Ai $\gamma \alpha$ í) está relacionada léxica y míticamente con una cabra $^{40}$. Imágenes de Perseo huyendo de las gorgonas también pueden verse en la diadema de

30 Calístenes, FGH 124 F40=Timeo, FGH 566 F155=Polibio XII 12b3. Cf. Ogden, 2011: 78; 214.

1 O’brien, 1992: 109.

2 Stewart, 1993: 246ss

3 Chiaro, 1981: 53-8; Grossman, 2001: 59-60.

4 Stewart, 1993: 239

35 Ov. Met. V 240-41; Lucan. IX 683; Athen. V 221C, sobre la mirada de Medusa.

36 Ogden, 2008: 114. Aunque la explicación que goza de mayor éxito entre los investigadores es que Pérdicas está relacionado con perdix (perdiz). Véase: Sturtevant, 1926: 244; Mallios, 2011: 212-3.

37 Smith, 1988: 41-2, destaca que la égida helenística busca la asociación con Zeus antes que con Atenea. Sobre la relación de los reyes de Macedonia con Zeus véase Le Bohec ( 2002: 41-57).

38 Wheeler, 2007: "Chilling sound" (97).

39 Leaky, 1856: 10, moneda con la cabeza de Medusa encontrada en Anfípolis.

40 Euphorion, fr. 34; Justin VII 1.7; Diod. VII 16. Cf. Girtzy (2001: 55). 
la tumba conocida como "the Lady of Aigai" "41 (c.500 a.C). Independientemente de si la tumba de Vergina es la de Filipo II $^{42}$ o Filipo III $^{43}$, el rey ocupante de la misma vistió una coraza de lino en la que destacaban dos impresionantes gorgonei $a^{44}$. En conclusión, existieron puntos de contacto míticos y materiales entre la égida y la casa real de Macedonia que permitían establecer una conexión entre ambos, aunque débil, antes del reinado de Alejandro Magno ${ }^{45}$.

¿Pretendían tener entonces los reyes macedonios la "capacidad", y por tanto la exigencia, de sembrar el terror en momentos concretos en sus adversarios?. No hay indicios suficientes para afirmarlo, pero, en cualquier caso, sí que parece que fue facultad de los reyes macedonios dialogar con lo sobrenatural:

"Él (Alejandro), por su parte, subió a la cima de una elevada montaña y, a la luz de gran cantidad de antorchas, hizo un sacrificio, siguiendo la costumbre de su país, a los dioses tutelares de la región (ipse in iugum editi montis escendit multisque conlucentibus facibus patrio more sacrificium dis praesidibus loci fecit)" ${ }^{\$ 46}$ (Traducción de Francisco Pejenaute Rubio, 1986).

No es nuestro objetivo cuestionar la identidad de esas deidades, puesto que independientemente de la misma el sacrificio de Alejandro tiene una función clara: conseguir el favor de los dioses para obtener la victoria en Issos. La víspera de Gaugamela se produjo una ceremonia similar. En esta ocasión se dice que Alejandro y Aristandro sacrificaron al dios del miedo, Phobos ${ }^{47}$. Phobos era un hijo de Ares y hermano de Deimos (terror) según Hesíodo (Teogonía 934), pero de acuerdo con Homero (Ilíada XI 35ss) Phobos y Deimos acompañaban a Medusa como cualidades naturales de la misma. El pasaje demostraría que todavía antes de consumar su fama de invencible, tanto el rey de Macedonia como sus soldados pensaban que existía un halo místico en su cargo que les permitiría vencer a través de sacrificios al miedo.

Desde nuestro punto de vista, las batallas de Issos y Gaugamela podrían verse del mismo modo, pues se consumaron gracias al hecho de que el ataque de Alejandro hizo retirarse a Darío III. Tanto Alejandro y sus hombres podrían haber destacado la cobardía del rey persa, no sólo como propaganda antiaqueménida ${ }^{48}$, sino también promacedonia al ensalzar el don de su rey para derrotar a sus enemigos por el miedo. En el Mosaico de Issos y en el Tetradracma de Poros, Alejandro es representado respectivamente poniendo en fuga a Darío ${ }^{49}$ y a un enorme elefante que podría haber estado dirigido por Poros ${ }^{50}$.

$\mathrm{Al}$ ser el miedo una emoción externa el incitador no habría tenido únicamente la capacidad de sembrar el pánico, también podría controlarlo o eliminarlo. Alejandro parece haber actuado de este modo cuando logró acabar con un ataque de pánico que se apoderó de todo su ejército ${ }^{51}$.

41 Kottaridi, 2011: 4.

42 Andronikos, 1978; Hammond, 1991.

43 Borza, 1981; Palagia, 2000.

44 Galanakis, 2011: 54; Graekos, 2011: 91.

45 Si los restos del rey enterrado en Vergina fuesen los de Filipo III, todo el ajuar funerario (cetro, coraza, casco, etc) incluidas las gorgoneia, podría pertenecer a Alejandro III, pues posiblemente Casandro enterró a los reyes (Adea-Eurídice y Filipo III) junto con los emblemas del conquistador. Cf. Borza ( 1987: 105-21).

46 Curt. III 8.22. Cf. Bing (1988: 161-5).

47 Plut. Alex. 31.4. Cf. Plut. Teseo 27; Cleómenes 9. Curt IV 13.15, dice que Alejandro y Aristandro sacrificaron antes de Gaugamela a Júpiter y a Minerva Victoria, dos portadores tradicionales de la égida.

48 Nylander, 1993: 145-59.

49 Stewart, 1993: 134ss.

50 Holt, 2003: 130.

51 Polyaen. IV 3.26; Curt. IV 12.16: "Alexander cognito pavore exercitus signum, ut consisterent, dari, ante ipsos arma deponere ac levare corpora iubet, admonens nullam subiti causam esse terroris, hostem procul stare". 
Sabemos que los Ptolomeos I, III, VI, VIII y XII vistieron la égida en las monedas que acuñaron $^{52}$. En las acuñaciones de Lisímaco, Atenea lleva la égida en su escudo ${ }^{53}$. Seleuco I acuñó monedas con la cabeza de Medusa ${ }^{54}$. Agatócles de Siracusa ${ }^{55}$, Antíoco III y Antíoco IV ${ }^{56}$ también se valieron de la égida como motivo iconográfico. El mensaje de las representaciones era evidente, los reyes que portaban la cabeza de Medusa eran invencibles (cf. Ilíada XXI 401).

Medio siglo después de la muerte de Alejandro, Antígono Gónatas dedicó a Pan su victoria contra los celtas con un poema escrito por Arato de Solos, pues el dios había sembrado el miedo entre sus enemigos ${ }^{57}$ Pese a que su padre, Demetrio Poliorcetes, le habría designado como su sucesor en el 288, no fue hasta el 277 cuando pudo proclamarse realmente rey gracias al prestigio que había obtenido por su victoria. La devoción de Antígono por este dios le llevó incluso a acuñar monedas con su efigie ${ }^{58}$. No se conservan muchas descripciones sobre el físico de Antígono, pero Plutarco habla de su fealdad (Moralia 458f) cuando relata cómo los habitantes de una ciudad se burlaron de su rostro. La historia es de veracidad dudosa, y la deformidad de Antígono parece estar inspirada en las monedas en las que los rasgos del rey se asemejan a los del dios Pan, hasta tal punto que provocan pavor en quien las mira ${ }^{59}$. ¿Es esta historia otro ítem más en nuestro estudio? Hay semejanzas con los casos anteriormente estudiados, pero se puede objetar que Pan no tiene relación ni con Perseo ni con Medusa. Sin embargo, uno de los epítetos conservados sobre este dios era el de Egipan, debido a que sus rasgos eran semejantes a los de una cabra, luego podría existir alguna vinculación entre la égida, es decir, la piel de la cabra Amaltea, y el dios Pan. En algunas versiones el joven dios fue alimentado por la propia Amaltea (Nonnus, Dionysiaca XXVII 290ss). En cualquier caso, infundir el pánico entre sus enemigos parece haber sido igualmente una cualidad de este dios ${ }^{60}$, por lo que la función de Pan sería la misma que la de la cabeza de Medusa. También está atestiguado su culto en Macedonia, ya que Arquelao encargó a Zeuxis un retrato del dios (Plin. XXXV 36.63). Curiosamente en el museo Arqueológico de Pela hay una estatua de Alejandro con los rasgos de Pan ${ }^{61}$, que también se había representado portando a Gorgo.

\section{CONCLUSIONES}

Los combates singulares, la invencibilidad, la seducción y atracción de soldados enemigos a su bando y su antítesis, el rechazo por el terror, forman parte de un mismo y único proceso: la construcción de la mística regia por parte de los reyes helenísticos. Se ha destacado la necesidad del monarca macedonio de vencer para convencer de su legitimidad, pero la victoria, pese a su incuestionable importancia, no fue el único elemento que sustentó los derechos al trono. El carisma personal de los individuos que detentaban el poder era igualmente importante. El rey era el mejor guerrero, el mejor cazador y el primero en competir por el honor. Ahora bien,

\footnotetext{
52 Ptolomeo I Soter (Hazzard, 1995: 432); Ptolomeo III (Johnson, 1999: 50). Cf. Smith ( 1988: 41; 44).

53 Dahmen, 2007: 159.

54 Houghton y Lorber, II 2002: 48-50.

55 Stewart, 1993: 432.

56 Callaghan, 1981: 59-70.

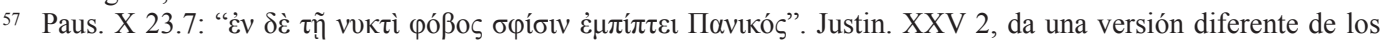
acontecimientos, pero también habla del miedo de los celtas. Cf. Pritchett, 1979: 32-4.

58 Gabbert, 1997: 68.

59 Cf. Leon (1989: 22.

60 Eur. Rhesos 36ss; Polyaen. I 2. En el escolio de Teócrito (V 16) Pan es definido como el inspirador del terror

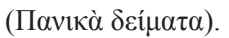

61 Stewart, 1993: 286-7; Svenson, 1995: 320.
} 
tras la muerte de Alejandro y la desaparición de la dinastía Argéada la proliferación de basileoi conllevó que la competición se extendiera entre déspotas que peleaban tanto por el dominio de un imperio único como por el de la excelencia absoluta. La capacidad de derrotar a un ejército por su presencia es la culminación de este proceso de mitificación, ya que se ha producido sin intermediarios e incrementa los méritos del vencedor, elevándolo por encima de otros rivales. El rey es capaz de atraer y repeler a sus enemigos al igual que la mirada de Medusa provoca fascinación y terror.

La lucha de Alejandro contra los malios es la base histórica para la construcción de los relatos que se crearon, y Aquiles poniendo en fuga al ejército troyano el sustrato mítico. Alejandro pudo presentarse como un nuevo Aquiles y hacer olvidar al mundo y a él que había estado a punto de morir en una pequeña aldea de la India. Pérdicas podía ser tanto un nuevo Alejandro como un nuevo Perseo, e imponer su autoridad al resto de los generales. Olimpíade tras derrotar por sí misma a todo el ejército de su gran rival Adea-Eurídice, se alzó por encima de su condición femenina, siendo capaz de hacer huir a los hombres de Casandro. La horrible muerte de Pirro, capaz de conmover a Antígono II Gónatas (Plut. Pirro 34.4-5), queda casi olvidada cuando leemos cómo detuvo la espada de su asesino con una mirada, aunque su destino fue el mismo que el de Medusa: decapitado por una espada curva ${ }^{62}$. El valor propagandístico de estas historias era elevadísimo.

Una última cuestión es si Alejandro fue el responsable de convertir al rey macedonio en un espantador de hombres o si fue el continuador de una tradición. Existió una relación mítica entre los Argéadas y Gorgo con anterioridad a su reinado, pero los restos materiales más interesantes, las gorgoneia de Vergina, pueden haber pertenecido tanto a Filipo II como a Alejandro. Ninguno de sus antecesores en el cargo nos ofrece algo exactamente igual a lo que hemos visto, pero los sacrificios de Alejandro y Aristandro antes de Issos y Gaugamela parecen sugerir algún tipo de ritual para invocar al miedo, en el cual el rey de Macedonia debía tomar parte. Ahora bien, ignoramos si estaba dirigido a Darío o todo el ejército enemigo ${ }^{63}$ y los diferentes nombres con los que se invoca al miedo en nuestro estudio (Phobos; Gorgo; Pan) ponen en duda la existencia de una forma concreta y ritualizada de llevar a cabo el objetivo de sembrar el pánico. Ante todo certifican una misma finalidad antes que una tradición, pero tal vez los macedonios tuvieron una deidad propia que pudo ser identificada por los griegos con estas tres personificaciones del pavor. Sin embargo, la égida fue un elemento común de todas las denominaciones usadas para invocar al miedo, por lo que podría paliar la ausencia de un único nombre.

Hay un posible precedente en tiempos de Filipo II, nos referimos al momento en el que Demóstenes, miembro de la embajada encargada de la paz de Filócrates (346 a.C), enmudeció de miedo ante el rey de Macedonia ${ }^{64}$ :

"Todos estaban así prestos para escucha; ese ser prodigioso balbucea un exordio oscuro y muerto de miedo. Y después de retroceder un poco a cosas anteriores se calla de repente y se

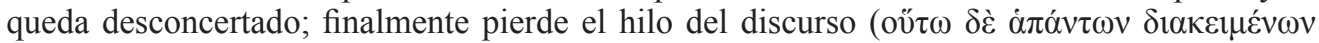

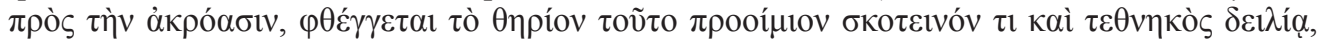

62 Todo el episodio de la muerte de Pirro tiene grandes similitudes con la de Medusa. Ambos son decapitados por espadas curvas. Pirro por una espada ilírica (thika), Medusa por una harpe, un arma utilizada tradicionalmente para matar drakontes (Ogden, 2008: 8). Tanto Medusa como Pirro lanzan miradas de espanto a sus asesinos (Perseo y Zópiro). Sus cabezas cercenadas siguen produciendo horror después de sus muertes y obligan al espectador a cubrirse para protegerse de su mirada (Plut. Pirro 34.4).

63 Las fuentes persas hablan de pánico absoluto en el ejército aqueménida como consecuencia del eclipse de luna ocurrido antes de Gaugamela. Cf. Rollinger y Ruffing (2012).

64 Worman, 2004: 15. 


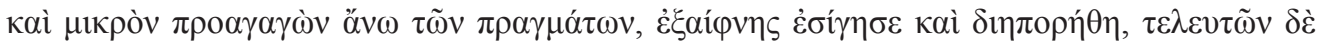

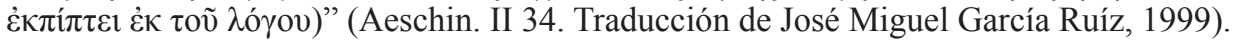

No es un combate real y podemos encontrarnos ante un tópos propio de la oratoria griega, pero la lectura es la misma, el carisma de Filipo II ha derrotado a su oponente, Demóstenes, el mejor orador de Grecia, dejándolo sin palabras a causa del miedo.

Igualmente interesante es un pasaje de Justino (VIII 2.3-6) en el que los macedonios se ponen coronas de laurel en la cabeza por orden de Filipo para aterrar a los focenses.

Hasta que la arqueología no traiga a la luz más información referente a las antiguas creencias religiosas de los macedonios todo esto no es más que una hipótesis de trabajo, pero merece la pena que se investigue más la naturaleza sagrada del rey macedonio y su influencia en sus sucesores helenísticos, antes de considerar a Alejandro Magno como un elemento de ruptura y completamente ajeno a su propia tradición cultural.

Terminamos citando una historia de Justino (VII 2.7-13) que refleja que la confianza de los macedonios en sus reyes excedía todo lo conocido:

"Los ilirios, pues, menospreciando la tierna edad de un rey huérfano, hacen la guerra contra los macedonios. Derrotados éstos en la batalla, llevando a su rey en la cuna y colocándolo detrás de las líneas, volvieron a la carga con más ardor, como si antes hubiesen sido vencidos porque en la lucha les habían faltado los auspicios de su rey, dispuestos a vencer de esta manera porque de esta superstición habían recibido su ánimo de victoria; al mismo tiempo también se apoderaba de ellos la compasión hacia el niño, al que creían convertir de rey en cautivo, si eran vencidos. Así pues, trabado combate, derrotaron a los ilirios con gran carnicería y mostraron a sus enemigos que a los macedonios en la guerra anterior les había faltado el rey, no el valor (ostenderuntque hostibus suis priore bello regem Macedonibus, non virtutem defuisse)" (Traducción de José Castro Sánchez, Madrid, Biblioteca Clásica Gredos, 1995).

Comprender la importancia de la monarquía macedonia es imprescindible para conocer la evolución de los reyes y del mundo helenístico durante sus primeros años, en los que el miedo infundido por el carisma regio fue un arma más en las manos de los Diádocos.

\section{BIBLIOGRAFÍA}

Ameling, W. (1988): “Alexander und Achilleus: ein Bestandsaufnahme", in W. Will and J. Heinrichs (eds.), Zu Alexander dem Grossen, Festschrift G. Wirth, II, 657-92.

Antela-Bernárdez, B. (2007): "Alejandro Magno o la demostración de la divinidad", Faventia, 29.1: 89-103.

Antela-Bernárdez, B. (2009): "Sucesión y Victoria. Una aproximación a la guerra helenística", Gerión, 27,1, 161-177.

Arriano. (1982): Anábasis de Alejandro Magno I-III. Madrid: Biblioteca Clásica Gredos. A. García Bravo (intr.); Antonio Guzmán Guerra (trad. y notas).

Arriano. (1982): Anábasis de Alejandro Magno IV-VIII (India). Antonio Guzmán Guerra (trad. y n.). Madrid: Biblioteca Clásica Gredos.

Austin, M. M. (1986): "Hellenistic kings, war, and the economy", $C Q, 36,450-466$.

Berve, H. (1926): Das Alexanderreich auf prosopographischer Grundlage, vols. I-II. Munich 19251926, reimpreso en New York 1973.

Bing, J. D. (1988): “Alexander's sacrifice dis praesidibus loci before the Battle of Issus”, JHS, 111, $161-5$

Borza, E. N. (1981): "The Macedonian Tombs at Vergina: Some Cautionary Notes", Archaeological News, 10, 1981, 73-87. 
Borza, E. N. (1987): "The Royal Macedonian Tombs and the Paraphernalia of Alexander the Great", Phoenix, 41, 105-121.

Borza, E. N. (1990): In the Shadow of Olympus. The Emergence of Macedon. Princeton.

Bosworth, A. B. (2002): Legacy of Alexander Politics, Warfare and Propaganda under the Successors, Oxford University Press.

Callaghan, P. (1981): “The Medusa Rondanini and Antiochus III", ABSA, 76, 59-70.

Carlier, P. (2000): "Homeric and Macedonian Kingship", in Alternatives to Athens. Oxford, 259-68.

Carney, E. D. (2006): Olympias: mother of Alexander the Great. London.

Chaniotis, A. (2012): "Moving stones. The Study of Emotions in Greek inscriptions". En A. Chaniotis (ed.), Unveiling Emotions. Sources and Methods for the Study of Emotions in the Greek World. Stuttgart, 91-129.

Chiaro, M. del (1981): “A monumental Etruscan head Medusa”, GettyMusJ, 9, 53-8.

Collins, A. W. (2001): "The Office of the Chiliarch under Alexander and the Successors", Phoenix, $55.3 / 4,259-283$.

Curcio Rufo, Q. (1986): Historia de Alejandro Magno. Madrid, Biblioteca Clásica Gredos. Francisco Pejenaute Rubio (trad. y n.)

Dahmen, K. (2007): The legend of Alexander the Great on Greek and Roman coins. New York.

Errington, R. M. (1969): "Bias in Ptolemy's History of Alexander", CQ, 19, 233-42.

Errington, R. M. (1974): "Macedonian 'Royal Style' and its Historical Significance", JHS, 94, 20-37.

Esquines. (1999): Discursos. Madrid, Ediciones Clásicas, José Miguel García Ruíz (trad.).

Gabbert, J. J. (2004): Antigonus II Gonatas: a political biography. London \& New York.

Gabriel, R. A. (2010): Philip II of Macedonia: Greater than Alexander. Washington.

Girtzy, M. (2001): Historical topography of Ancient Macedonia. Thessaloniki.

Grainger, J. (2007): Alexander the great failure: the collapse of the Macedonian Empire. London \& New York.

Granier, F. (1931): Die makedonische Heeresversammlung. Ein Beitrag zum antiken Staatsrecht. Munich.

Grossman, J. B. (2001): "Images of Alexander the Great in the Getty Museum", in Studia Varia, 5178.

Galanakis, Y. (2011): “Aegae: 160 years of archaeological research", in Heracles to Alexander the Great. Treasures from the Royal Capital of Macedon, a Hellenic Kingdom in the Age of Democracy. Oxford: Ashmolean Museum of Art and Archaeology, University of Oxford, 49-58.

Graekos, I. (2011): "War and hunting: the world of the Macedonian king and his companions", in Heracles to Alexander the Great. Treasures from the Royal Capital of Macedon, a Hellenic Kingdom in the Age of Democracy. Oxford, Ashmolean Museum of Art and Archaeology: University of Oxford, 75-92.

Guzmán Guerra, A. (1986): Alejandro Magno. Plutarco/Diodoro Sículo. Madrid: Akal.

Hammond, N. G. L. (1989): The Macedonian State. Origins, Institutions and History. Oxford 1989.

Hammond, N. G. L. (1990): "Royal Pages, Personal Pages and Boys Trained in the Macedonian Manner during the Period of the Temenid Monarchy", Historia, 39, 261-90.

Hazzard, R. A. (1995): “Theos Epiphanes: Crisis and Response”, HThR, 88.4, 415-36.

Heckel, W. (1992): The marshals of Alexander the Great. London.

Heckel, W. (2006): Who's who in the age of Alexander the Great. Prosopography of Alexander's empire. Blackwell.

Homero (1991): Ilíada. Emilio Crespo (trad. y n.). Madrid: Biblioteca Clásica Gredos.

Houghton, A. y Lorber, C. (2002): Seleucid coins: a comprehensive catalogue, I-II. New York.

Jacob, Ch. (1991): “Alexandre et la maitrise de l'espace”, $Q S, 34,5-40$.

Johnson, C. G. (1999): "The Divinization of the Ptolemies and the Gold Octadrachms Honoring Ptolemy III", Phoenix 53, 50-6.

Justino. (1995): Epitome de las filípicas de Pompeyo Trogo, J. Castro Sánchez (ed. y trad.). Madrid: Biblioteca Clásica Gredos.

Kottaridi, A. (2011): "The Legend of Macedon: a Hellenic kingdom in the age of democracy", in Heracles to Alexander the Great. Treasures from the Royal Capital of Macedon, a Hellenic Kingdom in the Age of Democracy. Oxford: Ashmolean Museum of Art and Archaeology. Oxford: University of Oxford, 1-24. 
Le Bohec, S. (2002): "The kings of Macedon and the cult of Zeus in the Hellenistic period", in D. Ogden (ed.), The Hellenistic world: new perspectives, Swansea, 41-57.

Leaky, W. M. (1856): Numismata Hellenica: a Catalogue of Greek Coins Collected. London.

Leon, C.F. (1989): “Antigonos Gonatas Rediscovered”, AncW, 20, 21-25.

Lock, R. A. (1977): "The Macedonian Army Assembly in the Time of Alexander the Great", $C P h, 72$, 91-107.

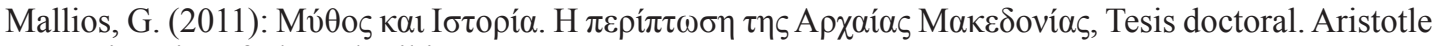
University of Thessaloniki.

Molina Marín, A. I. (2009): "Política y confrontación en los banquetes macedonios en la obra de Plutarco", in Symposion and Philanthropia in Plutarch. Coimbra: Universidad de Coimbra 2009, 201-9.

Molina Marín, A. I. (2012): Alejandro Magno. Apotheosis y Paideia. La figura del gobernante entre el homenaje y la teoría política: Editorial Académica Española.

Mossman, J. M. (1988): "Tragedy and epic in Plutarch's Alexander", JHS, 108, 83-93.

Nylander, C. (1993): "Darius III - the Coward King. Points and Counterpoints", in J. Carlsen et al. (eds.), Alexander the Great. Reality and Myth. Rome, 145-59.

O'brien, J. M. (1992): Alexander the Great. The Invisible Enemy. London \& New York.

Ogden, D. (2008): Perseus. New York: Routledge.

Ogden, D. (2011): Alexander the Great. Myth, Genesis and Sexuality: Univerty of Exeter Press.

Plutarco, (1968): Vidas paralelas. Barcelona, Editorial Vergara, Antonio Ranz Romanillos (trad.).

Plutarco, (1989): Obras Morales y de costumbres (Moralia), M. López Salva, (trad.). Madrid: Biblioteca Clásica Gredos.

Pritchett, W. K. (1979): The Greek State at War, III. London.

Roisman, J. (2003): "Honor in Alexander's campaign", in Brill's companion to Alexander the Great. Brill: 279-321.

Roisman, J. (2012): Alexander's Veterans and the Early Wars of the Successors, University of Texas Press.

Rollinger, R. y Ruffing, K. (2012): “ePanik' im Heer: Dareios III., die Schlacht von Gaugamela und die Mondfinsternis vom 20. September 331 v. Chr", Iranica Antiqua, XLVII, 101-115.

Romm, J. R. (2011): Ghost on the throne. The death of Alexander the Great and the war for crown and empire. New York.

Sawada, N. (2011): "Social Customs and Institutions: Aspects of Macedonian Elite Society", in A companion to Ancient Macedonia, Blackwell, 392-408.

Stewart, A. (1993): Faces of power. Alexander's image and Hellenistic Politics. Berkeley.

Sturtevant, E. H. (1926): "Centaurs and Macedonian Kings", $C P h, 21,3,235-49$.

Svenson D. (1995): Darstellungen hellenistischer Könige mit Götterattributten. Frankfurt.

Vernant, J-P. (1996): La muerte en los ojos. Barcelona: Gedisa.

Waterfield, R. (2011): Dividing the spoils. Oxford: Oxford University Press 2011.

Wheeler, E. L. (2007): The armies of classical Greece. Aldershot: Ashgate.

Worman, N. (2004): "Insult and Oral Excess in the Disputes between Aeschines and Demosthenes", $A J P h, 125,1,1-25$.

Yardley, J. C. y Atkinson, J. E. (2009): Curtius Rufus. Histories of Alexander the Great. Book 10. Oxford.

Recibido: 11/12/2013

Aceptado: 12/06/2014 